\title{
Turismo na pauta do rádio: o programa Coluna de Turismo em Ilhéus, Bahia
} (Brasil)

\section{Tourism on radio's schedule: the program Coluna de Turismo in Ilhéus, Bahia (Brazil)}

\author{
Charles dos Reis Alves (ALVES, C. dos R.) \\ Joliane Olschowsky da Cruz (CRUZ, J. O. da)
}

\begin{abstract}
RESUMO - Ao considerar que o residente é um importante fator de coesão para o desenvolvimento da atividade turística, objetiva-se ressaltar a possibilidade do rádio em inserir o morador nos debates acerca do turismo local. O objeto dessa análise é o programa Coluna de Turismo, que se propõe a discussão de temas referentes ao turismo no município de Ilhéus, Bahia (Brasil). A revisão bibliográfica parte de estudos sobre as características do rádio alinhados com a Teoria das Representações Sociais. São analisadas gravações radiofônicas e entrevista semiestruturada com o locutor do programa, tendo em vista a produção dos conteúdos veiculados. Evidencia-se o rádio como um espaço de mediação, propondo reflexões que contribuam para mudanças de representações, fazendo com que o residente perceba seu lugar como turístico e enxergue no turismo um importante vetor para o desenvolvimento local.
\end{abstract}

Palavras-chave: Cultura; Turismo; Representações Sociais; Rádio; Residente.

ABSTRACT - This work considers the resident as an important cohesive factor for tourism development, so the objective of this paper is to emphasize the possibility of radio inserting resident in discussions about local tourism. The object of this analysis is the program Coluna de Turismo, which aims to discuss issues relating to the tourism in Ilhéus, Bahia (Brazil). The literature review comes from studies related to characteristics of the radio aligned with the Social Representation Theory. Radio recordings are analyzed and also a semistructured interview was accomplished with the broadcaster of the program, to investigate the production of broadcast content. It is evident the radio as a mediation space, proposing reflections that contribute to

\footnotetext{
* Formação: Graduação em Comunicação Social (Bacharelado) e Mestrado em Cultura e Turismo pela Universidade Estadual de Santa Cruz (UESC). Atividade profissional: Produtor Cultural do Instituto Federal de Educação Ciência e Tecnologia de Goiás (IFG) - Campus Goiânia, onde também atua como professor no Programa Nacional de Acesso ao Ensino Técnico e Emprego (PRONATEC) nas áreas de comunicação e turismo. Tem experiência na área de produção televisiva e radiofônica. Desenvolve estudos principalmente nas linhas de pesquisa sobre rádio, sociedade, cultura e turismo. Endereço físico para correspondência: Instituto Federal de Educação, Ciência e Tecnologia da Goiás - Campus Goiânia, Coordenação de Comunicação Social, Rua 75, no 46, Setor Central. CEP: 74055-110 - Goiânia (Goiás) Brasil. Telefone: (62) 3227-2876. E-mail: charles.alves@ifg.edu.br.

** Formação: Graduação em Física pela Universidade de São Paulo (USP), Mestrado e Doutorado em Ciências da Comunicação pela ECA-USP. Atividade profissional: Professora e pesquisadora da UESC, atuando na graduação em Rádio e TV. Lecionou no Mestrado em Cultura e Turismo, através da linha de pesquisa Fotografia e Representações Sociais. Experiência em Comunicação, ênfase em Comunicação e Estética do Audiovisual. Projetos de pesquisa Representações Sociais em Imagens e Comunidades tradicionais e suas relações com o turismo no sul da Bahia. Endereço físico para correspondência: UESC Rod. Jorge Amado, Km 16, DLA, $2^{\circ}$ andar, Pav. Adonias Filho, Lab. Fotografia (Bairro Salobrinho). CEP: 45662-900 - Ilhéus (Bahia) - Brasil. Telefone: (73) 3680 5289. E-mail: jocruz@uesc.br.
} 
representation changes, making the resident realize this place as tourist and recognize in tourism business an important mean for local development.

Key words: Culture; Tourism; Social Representation; Radio; Resident. 


\section{INTRODUÇÃO}

Durante a primeira metade do século XX o rádio se destacou como veículo promotor da cultura nacional. Com o rádio, e posteriormente com o cinema, a imagem da cultura nacional foi apresentada aos próprios brasileiros, projetando também a imagem do país para o exterior, fomentando o turismo (SÁ, 2002). Hoje, quase centenário, o rádio parece se revigorar com as tendências da digitalização (BIANCO, 2004). Aliás, superação e reinvenção são características do veículo. Foi assim com a chegada da TV, quando o rádio abandonou o caráter nacional e voltou-se ao regionalismo (COMASSETTO, 2007). Posteriormente, experimentou a ascensão da frequência modulada e reformulou a programação (ORTRIWANO, 1985). Também democratizou seu espaço com o surgimento das rádios comunitárias (COGO, 1998). Com a linguagem coloquial e intimista, o meio penetrou em suportes diminutos, do radinho de pilha ao $\mathrm{mp} 3^{1}$.

Embora muitas pesquisas na área do turismo atentem para o papel dos meios de comunicação, escassos são os estudos que alinham o turismo e a mídia radiofônica. Ao considerar que o residente é um importante elo para o desenvolvimento da atividade turística, foi de interesse avaliar a possibilidade do rádio em inserir o residente nos debates acerca do turismo local, originando pesquisa de mestrado ${ }^{2}$ que investigou as Representações Sociais (RS) relacionadas à cultura e ao turismo na cidade de Ilhéus, Bahia (ALVES, 2012).

As pessoas viajam para conhecer o outro, pois lugares são valorizados por seus atributos físicos e simbólicos e ainda por refletirem práticas sociais diferentes. Assim, é preciso atentar para as representações sociais que os sujeitos têm dos destinos turísticos. Nesse contexto, a Teoria das Representações Sociais (RS) de Moscovici (2003) torna-se pertinente para o entendimento da construção de sentido que o homem estabelece ao relacionar-se com o meio em que vive. As representações, que surgem e existem nos processos comunicativos, também se modificam através destes processos. Assim, investigou-se como o veículo rádio pode assumir a função de estimular mudanças

\footnotetext{
${ }^{1}$ Aparelho que reproduz arquivo de áudio digital. Também se refere ao formato de arquivos digitais de áudio que tiveram seu tamanho original reduzido.

${ }^{2}$ Realizada no Programa de Mestrado em Cultura e Turismo da Universidade Estadual de Santa Cruz.
} 
comportamentais, podendo promover a valorização da cultura e o desenvolvimento local por meio do turismo.

A cidade de Ilhéus, Bahia, foi escolhida para o estudo por dois motivos: primeiro, por sua vocação turística; e segundo, por possuir uma emissora comunitária que veiculava um programa radiofônico voltado para o turismo: o Coluna de Turismo.

Desde sua doação a Jorge de Figueiredo Correia, em $1^{\circ}$ de abril de 1535 , a capitania de Ilhéus, localizada onde ficou conhecido como Costa do Pau-Brasil, experimentou diversas fontes econômicas, do extrativismo do pau-brasil à lavoura de cana-de-açúcar, chegando à exploração do cacau (BUENO, 1999). Banhado por 83 km de praias, atualmente o município de Ilhéus experimenta o turismo de sol e praia.

Integrando a Costa do $\mathrm{Cacau}^{3}$, a atividade turística também se utiliza da história do município, marcada pelos períodos de colonização que deixaram um legado cultural constatado na arquitetura, para desenvolver-se. Outra herança são suas manifestações culturais, algumas delas originadas no contato entre povos indígenas, negros e brancos, com fortes influências religiosas. As características do município e seu povo, como as disputas por terra, as hierarquias de poder, as lendas, que extrapolaram os limites geográficos e alojaram-se no imaginário cultural através de estereótipos germinados pela literatura de autores como Adonias Filho e Jorge Amado, também se configuram como potenciais atrativos. Aliadas a presença da Mata Atlântica, as antigas fazendas de cacau têm se mostrado importante possibilidade para o turismo rural (BAHIA, 2001).

Em 1950, Ilhéus foi a primeira cidade da região sul da Bahia a receber uma emissora de rádio, a Rádio Cultura de Ilhéus, seguida por Itabuna, que recebeu a Rádio Clube de Itabuna, em 1956, com a ideia de atender aos interesses do coronelismo (PAULA FREITAS et al, 2006). Atualmente, de acordo com a Agência Nacional de Telecomunicações (ANATEL, 2013), a cidade de Ilhéus conta com 6 emissoras de rádio, sendo 5 rádios comerciais e 1 comunitária, a Rádio FM Conquista, que veiculava o programa Coluna de Turismo.

O programa Coluna de Turismo era veiculado diariamente (segunda a sexta-

\footnotetext{
${ }^{3}$ No Mapa da Regionalização do Turismo na Bahia, o estado foi dividido em treze regiões. Ilhéus integra a Costa do Cacau, criada com a finalidade de viabilizar o foco turístico característico do histórico cultural e natural dessa região do estado. Além de Ilhéus, compõem a Costa do Cacau: Itacaré, Uruçuca, Itabuna, Una, Santa Luzia, Canavieiras e Pau Brasil (BAHIA, 2001).
} 
feira), durante meia hora. Sob o comando do turismólogo Ariel Figueroa ${ }^{4}$, o programa destinava-se a discutir temas referentes ao turismo local, suscitando debates sobre a sustentabilidade econômica, cultural, ambiental e social, com a proposta de colocar o turismo em pauta, apresentando uma vertente educativa, para levar o morador a descobrir e reconhecer o potencial do seu município. Essas e outras informações sobre o programa, apresentadas no decorrer do artigo, foram extraídas de entrevistas com o locutor e apresentador, e com os radialistas ${ }^{5}$ de Ilhéus, realizadas durante a coleta de dados da pesquisa de mestrado (ALVES, 2012).

A amostra desse estudo constituiu-se de dez programas radiofônicos, com duração de trinta minutos cada, veiculados em janeiro e fevereiro de 2011 (alta temporada em Ilhéus) conforme a disponibilidade dos arquivos cedidos pelo locutor no período. Com a finalidade de averiguar como estava sendo produzida a programação diferenciada em função do turismo, entender as escolhas de conteúdos e como o locutor percebia a cultura e o turismo local para o desenvolvimento do município, aprofundouse a investigação com entrevista semiestruturada realizada em 15 de junho de 2011. A título de contextualização transcreveu-se algumas falas do locutor durante o primeiro programa veiculado em 18 de janeiro de 2010.

\section{O PAPEL DO RÁDIO NA DIFUSÃO DAS REPRESENTAÇÕES SOCIAIS}

Nas representações das culturas, o turismo, caracterizado pela imaterialidade, encontra na mídia uma forma de materializar-se, despertando expectativa nos consumidores em relação aos destinos. No sistema de movimentação cultural o rádio merece destaque por apresentar-se, também, como um meio de integração social, cultural e política. Partindo da oralidade, o veículo permite avaliar imagens mentais verbalizadas, reafirmando valores e representações, na medida em que cria imagens a

\footnotetext{
${ }^{4}$ Ariel Figueroa, natural do Uruguai, graduado em Turismo, tem Especialização em Políticas Públicas e Mestrado em Administração Hoteleira e mora no Brasil há 30 anos. Comandava o programa Coluna de Turismo na rádio FM Conquista de Ilhéus (ALVES, 2012).

${ }^{5}$ Outros radialistas, diretores de programação das rádios comerciais, foram entrevistados na pesquisa de mestrado, mas suas falas não estão transcritas neste artigo: Rádio Santa Cruz (Gil Gomes), Rádio Cultura de Ilhéus (Malthez de Athaíde), Rádio Bahiana (Hécliton Alves), Rádio Gabriela FM (Renato Nogueira).
} 
partir dos recursos sonoros (palavra, música, sonoplastia ${ }^{6}$ ) e não sonoros (silêncio).

A linguagem radiofônica é capaz de sintetizar códigos acessíveis a vários grupos sociais e, por esse motivo, o veículo tem a capacidade de atingir e ser compreendido por um público muito diversificado. Por meio do seu vocabulário coloquial, o veículo é direto e persuasivo. Mobilidade, portabilidade, acessibilidade, imediatismo e instantaneidade, são características que lhe permitem estar sempre em contato com a realidade dos ouvintes, possibilitando sua integração com um amplo mundo (ORTRIWANO, 1985).

Essas características lembram o princípio: o meio é a mensagem. A natureza do meio também é um conteúdo. Isso conduz à percepção de que todo meio atua como ambiente simbólico, já que constrói seu modo de comunicar e entender o mundo. Sugerindo que o sistema nervoso central humano ajusta-se às informações difundidas pelos meios, a teoria de McLuhan (2003) relata que as novas tecnologias da informação seriam a causa e o motivo das estruturas sociais. Nesse contexto, o rádio deve ser usado para viabilizar transformações sociais propondo novas abordagens para temas importantes para a comunidade.

No processo de mediação, o profissional de rádio aparece como elemento central favorecendo as negociações e construções de significados com o receptor, pois “detém o poder de estabelecer os limites dentre os quais se fará esta intermediação e o próprio espaço de ação, que terão as demais partes envolvidas nos conflitos a ele apresentados" (ESCH, 2001, p. 83). Na interação social, Santos (2004) afirma que, através da fidelidade dos ouvintes, os locutores adquirem ao longo dos anos uma espécie de capital cultural, uma personificação que os qualifica como especialistas, cujas palavras se tornam palavras de ordem, às vezes, aceitas como verdade absoluta.

Se os radialistas detêm conhecimento sobre a realidade, no rádio essa realidade exterior percebida transforma-se em representação mental através da oralidade. O meio disponibilizado para difusão de mensagens pressupõe estratégias que levam em consideração o uso dos recursos cognitivos e a valorização emocional do que é veiculado (ARNHEIM, 2005; MCLUHAN, 2003). Assim, as imagens formadas nas mentes dos ouvintes encontram suporte nas falas dos locutores, que carregam consigo discursos ancorados nas experiências cotidianas, nas convenções culturais.

\footnotetext{
${ }^{6}$ Sonoplastia é a utilização de efeitos sonoros diversos para apoiar a construção de sentido do texto radiofônico, já que o rádio é um veículo eminentemente sonoro.
} 
Conforme Comassetto (2007), a programação de uma emissora de rádio se especializa, sobretudo, no que diz respeito à localidade. Assim, ao comunicar-se com os moradores a respeito do turismo, o veículo poderia: ajudar no processo de valorização do patrimônio local; disponibilizar opções de lazer como bares, restaurantes, eventos festivos e culturais, as condições das praias e a temperatura do ar; favorecer a cultura local através das músicas e artistas regionais; por meio da locução, evidenciar a variedade linguística regional, estimando as referências culturais. Além disso, com programas informativos, também poderia viabilizar maior circulação de pessoas nos períodos de sazonalidade, levando os residentes a apreciar os eventos e vivenciar sua própria cultura, movimentando a economia.

Esse tipo de ação é importante para que a população local se aproprie do seu ambiente enquanto lugar turístico. O desenvolvimento turístico não pode prescindir de um processo de familiarização do morador com o seu espaço, reconhecendo-o enquanto espaço singular e atrativo. A Teoria das Representações Sociais (RS) de Moscovici (2003) leva a compreender o processo de familiarização e atribuição de significados ao estabelecer-se contato com o mundo físico.

Construídas nas interações sociais difundidas por meio da comunicação, as RS são absorvidas pelas pessoas e passam a pertencer ao senso comum. Ideologias são incorporadas a essas representações, atribuindo outros valores, guiando os comportamentos em relação aos objetos representados. Estando em constante transformação, as RS são a base para produção de conhecimento, ligadas à produção de sentido, de opinião e de imagens mentais sobre os diversos objetos do mundo (MOSCOVICI, 2003).

A teoria de Moscovici (2003) traz que as RS estão diretamente vinculadas às histórias e às culturas dos indivíduos, bem como estão no contexto das vivências e experiências compartilhadas com os outros. As representações sustentam as identidades das pessoas, isso significa afirmar que desconstruir ou interferir nas representações implica uma mudança de percepção sobre o mundo e, consequentemente, transformações na identidade.

Assim, tudo o que não é familiar incomoda e é então que surge o processo de categorizar as coisas, pessoas e acontecimentos para poder lidar com o assunto, objeto ou situação. Na formação das representações, Moscovici (2003) mostra a importância 
dos processos que atuam conjuntamente: ancoragem e objetivação. A ancoragem é o artifício pelo qual algo que é estranho passa a ser confrontado com um paradigma existente na memória, mesmo que seja para garantir um pouco de coerência entre o que é desconhecido e o que já faz parte desse universo. Por isso, ancorar é admitir o que é novo.

Objetivação é o processo de contextualizar as ideias. É a fase em que a palavra transforma-se em imagem. É nesse momento que o invisível torna-se visível na mente. O desconhecido deixa de ser ameaçador, passa a ser objeto familiar e a representação é aceita e difundida, através da comunicação, constituindo um núcleo central que irá permanecer intacto até que uma nova representação surja ou que o modifique (MOSCOVICI, 2003).

Desta forma, entende-se a influência direta que o rádio pode ter no processo de RS no turismo, estruturando o senso comum, favorecendo o estabelecimento de novas associações à realidade do ouvinte. Seu poder pode estar na capacidade de construir e difundir representações e orientar pessoas. É por meio desse processo que o veículo pode construir e desconstruir as percepções dos ouvintes-residentes sobre sua localidade, abarcando o papel de agenda coletiva social (PENA, 2005).

É pelo caráter eminentemente local da programação radiofônica, e pela proximidade que o veículo mantém com os ouvintes, que se destaca o rádio como meio de acesso à história e cultura de Ilhéus. Sua função deve ser a de difundir ideias, elementos da cultura, tradições e hábitos sociais, oferecendo mecanismos de formação e integração, estimulando o lazer, a cultura e o convívio social (ANATEL, 2013). Analisa-se, nessa perspectiva, o programa Coluna de Turismo.

\section{DO IMPRESSO AO SOM: GÊNESE DO PROGRAMA}

O programa radiofônico Coluna de Turismo surgiu de uma coluna publicada em jornal impresso, Jornal Foco Bahia (ALVES, 2012). O locutor - e apresentador - do programa ressaltou que a migração para o rádio foi devida à potencialidade do veículo em difundir informação por meio da sua abrangência e penetrabilidade: 
[...] em termos numéricos a minha coluna, que acontece no Jornal Foco Bahia, é (sic) é uma tiragem [...] de 5.000 exemplares quinzenais; o meu site, colunadetursimo.com.br, tem uma audiência de 1.200 a 1.500 pessoas/dia, que para site pequeno do nordeste é boa. Agora, o programa tem de 13 mil a 15 mil pessoas/dia e estamos online, [...] não consigo ainda mensurar, que me (sic) chegam e-mails de Angola, de Portugal, da Espanha, da Argentina, do Uruguai, é (sic) de São Paulo, é (sic) [...] (FIGUEROA, jun. 2011).

Ele também mencionou que a escolha do veículo levou em consideração a possibilidade do rádio permitir ao locutor o estabelecimento de uma intimidade com o ouvinte para falar com o morador, de forma franca, direta e provocativa, estabelecendo um diálogo onde ambos poderiam ser emissores e receptores de informação. Essa interatividade reforçava a possibilidade de influenciar o ouvinte, assim, o locutor apostou na participação como um caminho para mudar a mentalidade da população em relação ao turismo:

[...] Não foram poucas as minhas provocações [...] Vão continuar acontecendo. [...] eu entendo o seguinte: Ilhéus, antes de mais nada, precisa aceitar o turismo. Ilhéus até hoje não aceitou, mas não aceitou por quê? Não aceitou porque não há um planejamento. Ilhéus não tem até hoje um planejamento estratégico que possa mostrar à população, aos empresários, metas e objetivos claros e o que vão (sic) se ganhar com isso (FIGUEROA, jun. 2011, grifo nosso).

A aceitação do turismo por parte dos residentes é importante para que se desenvolva uma atividade turística equilibrada. Informação pode possibilitar a reflexão sobre vantagens e desvantagens do turismo para Ilhéus, favorecendo a mudança de RS. O locutor ressaltou, no primeiro programa analisado, que esse conhecimento difundido poderia amenizar conflitos dos residentes em relação à prática do turismo.

\footnotetext{
Lamentavelmente a gente ouve pelas ruas que o turista incomoda. Que o turista enche a rua, que o turista enche as barracas de praia, que o turista ocupa com os seus veículos o estacionamento da [avenida] Soares Lopes. Então é uma coisa perigosa, contraditória. Todo mundo acha que o turismo é necessário, mas quando o turista chega, ele incomoda. Nós precisamos, antes de mais nada, dizer sim para o turismo (FIGUEROA, jan. 2010).
}

O programa era apresentado na Rádio Bahiana de Ilhéus e apesar da importância na grade, pelos temas relevantes, o programa não pôde permanecer no ar, pois os radialistas (filiados ao Sindicato de Radialistas de Ilhéus) questionaram o fato de o locutor ser formado em turismo e não possuir registro profissional de comunicador 
junto a Delegacia Regional do Trabalho (DRT) (ALVES, 2012). Para além dos direitos de transmissão radiofônica, percebe-se o prestígio e a influência do veículo perante a comunidade e a visibilidade do comunicador torna o rádio um espaço de legitimação (SANTOS, 2004).

Após sair da Rádio Bahiana de Ilhéus, o programa migrou para a rádio comunitária FM Conquista, onde estreou em 18 de janeiro de 2010. No primeiro programa, o locutor explicou aos ouvintes que a atividade turística é boa para quem visita, por possibilitar novas descobertas e esclareceu o principal mote do programa, conforme trecho extraído da estreia:

\begin{abstract}
O que nós queremos com um programa sobre turismo? Bom, antes de mais nada, nós entendemos [...] que se é bom para o turista, irremediavelmente tem que ser bom para o morador. [...] se nós não estamos satisfeitos, se nós não estamos gostando de como está o município, de como está a cidade, irremediavelmente, não tenha a menor dúvida, o turista não vai gostar. É por isso, que com essa ideia, que com essa emoção, com esse sentimento de querer construir, de querer dialogar, de querer discutir o que está acontecendo na nossa cidade, para que [...] o turismo seja de vez, mas realmente, realmente, um dos vetores de sustentabilidade financeira, social e ambiental do nosso município (FIGUEROA, jan. 2010, grifos nossos).
\end{abstract}

Pelo caráter comunitário da emissora, que tende a abrir espaço para a expressão da comunidade, o locutor sentia necessidade de ampliar os espaços de discussão, tendo em vista que a pretensão era fazer um programa educativo e não apenas informativo.

Quando iniciamos [...] meia hora para mim era um século. [...] eu ficava apavorado e dizia: o que é que eu vou falar todos os dias sobre turismo. [...] Hoje não tem mais condições do programa ter meia hora. Eu me sinto completamente encaixotado, engaiolado [...] (FIGUEROA, jun. 2011).

Frente ao desejo de ampliar a duração do programa estavam os interesses da emissora que, na época da coleta de dados, tinha como concessionário um pastor. Não havia tempo suficiente para música, além de determinados assuntos ficarem fora da pauta.

A rádio é uma rádio evangélica. Queria que isso ficasse muito claro, porque em determinados aspectos limita alguns tipos de atividades. É (sic) a música... O programa também é de meia hora, esse é um projeto que nós temos agora para o mês de junho, estamos entrando como Coluna de Turismo como rádio online também, e a gente vai poder se manifestar em cima de (sic) música é (sic) que a gente gosta, né? (FIGUEROA, jun. 2011). 
Com esse formato, o programa permaneceu na Rádio Conquista FM durante o primeiro semestre, migrando para a internet em 29 de agosto de 2011 (ALVES, 2012). Para o locutor, a mudança levava em consideração tais limitações, mas também tendia a reduzir custos de produção e atingir um público maior. O aumento de tempo de veiculação e abrangência a qualquer parte do mundo, entretanto, tirava do programa o diálogo com a comunidade, seu principal valor, sobretudo os excluídos da grande rede mundial de computadores.

Em 26 de março de 2012, com parte de suas revindicações atendidas, o programa Coluna de Turismo retornou à Rádio FM Conquista. Tendo uma hora de duração, e veiculação de segunda a sexta feira, das $13 \mathrm{~h}$ às $14 \mathrm{~h}$, até o dia 11 de maio de 2012 quando, por divergências com a linha editorial da emissora, o programa deixou de ir ao ar na Rádio (ALVES, 2012). Segundo o locutor, a emissora vetou a veiculação do programa pela internet. Tal circunstância reafirma que, em alguns casos, o caráter comunitário não garante democracia nas tomadas de decisão e planejamento da comunicação, desafio para os setores que desejam construir uma comunicação plural (COGO, 1998).

\subsection{ESTRUTURA DO PROGRAMA COLUNA DE TURISMO}

Diante das mudanças ocorridas no programa Coluna de Turismo, cabe reforçar que os dados analisados neste artigo compreendem aos programas veiculados nos meses de janeiro e fevereiro de 2011, quando cada programa possuía apenas trinta minutos de duração.

O programa caracterizava-se como programa de variedades ${ }^{7}$ e inseria-se no gênero especial (BARBOSA FILHO, 2003), que recebe essa denominação por não possuir uma função específica como outros gêneros radiofônicos; era estruturado em três blocos (abertura, primeiro bloco e segundo bloco) intercalados por intervalos

\footnotetext{
${ }^{7}$ Formato de programa que mescla notícias, entrevistas, música. Sua duração pode variar, mas geralmente é formatado de 15 a 30 minutos, intercalado por comerciais. Outros gêneros são: jornalístico, publicitário, entretenimento.
} 
comerciais. Embora proibida ${ }^{8}$ para o tipo de concessão da emissora (BRASIL, 1998), a publicidade ocupava um tempo pequeno e seu conteúdo não estava diretamente ligado à divulgação do turismo e da cultura local (ALVES, 2012).

$\mathrm{Na}$ vinheta de abertura do programa apresentava-se o nome do locutor e ressaltava-se o eixo principal dos debates: Ariel Figueroa, tratando o turismo com responsabilidade. A entrada do locutor ao vivo seguia as estruturas básicas dos programas radiofônicos, com cumprimentos ao ouvinte, informação com a hora certa, seguida da contextualização do clima e tempo na cidade. Destacava-se, nesse momento, o sol e o clima de verão, relacionando-os ao clima baiano. Ainda na abertura, o locutor apresentava as manchetes do dia, posteriormente desdobradas (ALVES, 2012).

O primeiro e o segundo blocos constituíam partes maiores do programa, destinadas a discutir e debater os assuntos da pauta, produzida de acordo com a percepção do locutor a respeito dos temas que julgava mais relevantes para a discussão.

[...] eu fazia uma pauta (sic) eu parava uma hora antes das minhas atividades para fazer a pauta... o fato de estar, naquele momento, alimentando meu blog, o meu site, já me dava uma (sic) uma certa bagagem para o programa, estando afinal no dia-a-dia da cidade, do estado e do Brasil (FIGUEROA, jun. 2011).

Essa subjetividade, aliada à falta de formação específica na área de jornalismo ou de radialismo, evidencia que a produção de conteúdos muitas vezes não levava em consideração os princípios de redação do jornalismo, ou pelo menos isso não era feito de modo consciente. A equipe de trabalho (locutor e operador de áudio ${ }^{9}$ ) dividia o estúdio (ALVES, 2012). Em alternados dias da semana, porém, o programa contava com convidados para debater determinados assuntos; especialistas (ou pessoas com papel social de destaque na cidade) atuavam como parceiros do programa e sustentavam o debate:

Hoje eu tenho três quadros. As segundas-feiras nós temos o pastor Gilmar Bonfim, com o qual conversamos sobre coisas da vida. Entra turismo e entra o dia-a-dia com outra óptica. [...] nós temos Antônio Olímpio [...] ex-prefeito

\footnotetext{
${ }^{8}$ De acordo com a Lei no 9.612 , de 19 de fevereiro de 1998, que instituiu o Serviço de Radiodifusão Comunitária, as emissoras comunitárias não podem veicular publicidade. O Art. 18 menciona que as marcas que apoiam os programas e/ou a rádio devem ser identificadas como Apoio Cultural.

${ }^{9}$ Profissional responsável pelo tratamento da voz, controle de ruídos, pela inserção de comerciais, trilhas, efeitos sonoros, vinhetas e outros detalhes que aparecem na hora que o programa de rádio está no ar.
} 
de Ilhéus, é... (sic) presidente da MARAMATA ${ }^{10},[\ldots]$ temos o quadro Coisas de Ilhéus, resgatando elementos históricos, elementos culturais, [...] E ele gosta de culinária, gastronomia é uma coisa muito importante dentro do turismo. [...] Às sextas-feiras nós temos o Israel Nunes, que é promotor federal, com o qual conversamos de direitos do consumidor (FIGUEROA, jun. 2011).

Os assuntos dessas entrevistas levavam em consideração as possíveis contribuições dos especialistas, tratando os fatos no contexto do turismo. Na mesma perspectiva, havia participação dos ouvintes que dialogavam com o locutor e convidados, embora a duração do programa não possibilitasse maior interatividade. (ALVES, 2012).

A locução final seguia a mesma estrutura em todos os programas, sendo possível perceber como o locutor encarava a penetrabilidade do veículo ao despedir-se do público com a seguinte frase: "Eu preciso agradecer que (sic) você permitiu que eu entrasse na sua casa, no seu trabalho, no seu carro, mp3, mp4, celular, radinho de pilha, enfim minha gente... Gente, muito obrigado! Se Deus quiser amanhã tem mais Coluna de Turismo e eu? Eu fui!" (FIGUEROA, jan. 2011).

\section{DEBATENDO O TURISMO COM RESPONSABILIDADE: PAUTAS}

Durante a descrição e análise dos conteúdos abordados nos dez programas que compõem a amostra de parte da pesquisa, evidenciou-se grande diversidade de temas. Quase todos os debates foram em torno do turismo. Tal constatação ratifica a visão holística do locutor do programa. Conforme ele destacou:

Por que fazer um programa sobre o turismo? Primeiro que ele é uma das
vertentes econômicas mais importantes do mundo [...] Eu não sei porque
ainda (sic) as pessoas não se antenaram (sic) para essa obviedade de (sic) ter
um programa de turismo. Porque, veja bem, turismo não é viajar. Turismo é
encontrar atividades, pessoas, elementos naturais, elementos culturais, que
interajam com o turismo. Aí você viaja e você não pega (sic) um avião, cê
(sic) vai primeiro para um aeroporto, cê (sic) passa por infraestruturas. [...]
sempre estamos falando: "ah, mas eu não sou bem atendido". Será que a
educação no Brasil está satisfeita? (sic) É isso que nós queremos? Chegamos
num patamar ideal ou ainda temos muito para construir? [...] Então o turismo
ele tem que perpassar por saúde, educação, infraestrutura, segurança,
iluminação, coleta de lixo... perpassa pelo dia-a-dia de uma cidade, de um

${ }^{10}$ Fundação Universidade Livre do Mar e da Mata. 
município, de um país. Então a abrangência desses assuntos é fantástica, é isso que estimula (FIGUEROA, jun. 2011).

Partindo do princípio de pesquisadores (CORIOLANO, 1998; IGNARRA, 2003; TRIGO, 2004) de que o turismo é um fenômeno complexo, no sentido de não se restringir ao deslocamento geográfico que o turista faz durante a viagem e visitação, mas, sobretudo, porque congrega diversos atores, suportes e interesses distintos na atividade, elencou-se em alguns grupos as pautas debatidas como: infraestrutura, gestão do setor, incentivo à arte, à cultura e ao lazer, meio ambiente, divulgação de campanhas e serviços. Devido ao dinamismo da atividade turística, nota-se que esses temas não se isolam e por vezes estão imbricados.

\subsection{INFRAESTRUTURA DO MUNICÍPIO}

O tema infraestrutura era latente em muitas circunstâncias. A abordagem referenciava tanto fatos locais quanto nacionais que teriam implicação direta no turismo da cidade. A contextualização reiterava o que pregam as teorias do rádio no que diz respeito ao papel do veículo de situar o ouvinte sobre a localidade e o mundo a sua volta. Usou então a declaração da presidente Dilma quando tratou da importância de ampliar os aeroportos brasileiros, para discutir os problemas no aeroporto de Ilhéus, principalmente no que se refere às limitações no tamanho das aeronaves devido ao tamanho da pista e da curta área de escape que limitaria embarques e desembarques.

Outra implicação na área dos transportes, a presença de bloqueio natural separando áreas de grande circulação de pessoas, nesse caso o rio Cachoeira, foi destacada pelo problema de congestionamento na Ponte Lomanto Júnior, uma via importante que liga o Centro de Ilhéus ao Bairro Pontal, área onde se situa o aeroporto Jorge Amado e a orla sul da cidade, onde se localizam as cabanas que recebem turistas. Essa discussão apareceu em dois programas, suscitada pelo próprio ouvinte em uma das ocasiões.

No que diz respeito à infraestrutura de pontos turísticos, desdobrou-se discussões sobre a demolição das barracas de praia localizadas na orla de Ilhéus. Falou-se sobre acordo entre a União, a Prefeitura Municipal e cabaneiros para prolongar o prazo de funcionamento das barracas até o carnaval, alertando que para impedir a demolição das 
cabanas, a prefeitura precisaria apresentar ao governo federal um projeto arquitetônico e urbanístico que contemplasse as novas exigências. O locutor criticou o Conselho de Desenvolvimento Econômico do Município, que estaria inerte à questão.

$\mathrm{Na}$ abordagem, a maior implicação em demolir as cabanas de praia seria a perda de espaços para o lazer dos turistas, tendo em vista que esses equipamentos ofereceriam a melhor infraestrutura, embora não fosse ainda a mais adequada. Nesse sentido, ressaltou a importância de investimentos em outros locais como o Rio do Engenho e Lagoa Encantada para propiciar mais lugares para o lazer e visitação turística.

Os problemas com pontos turísticos da cidade apareceram em outros programas. Foi destacada a falta de iluminação, segurança e higiene no centro da cidade, principalmente nas proximidades da Catedral de São Sebastião. Foi abordada também a falta de toldo para recepcionar os turistas que desembarcavam dos cruzeiros, alegando a necessidade da estrutura principalmente na época do verão.

Com a proximidade do carnaval a discussão passou a ser o número de policiais recrutados para cuidar da segurança da festa. A preocupação maior era que o efetivo não conseguisse coibir o tráfico e uso de drogas, bem como a violência no local, devido a extensão do circuito e as estratégias dos bandidos para esconder armas na praia.

No contexto de preparar a cidade para receber o turista, discutiu-se as novas tecnologias, seus suportes, utilização e aplicações no turismo. Destacou-se especialmente o celular, enquanto meio portátil, e a internet na obtenção de informações tais como: locais para cultura e lazer, lugares para hospedagem, serviços de táxi. Maior destaque dado ao fato do celular poder ser conectado à internet tornando-se um potente difusor de imagens. O locutor ressaltou a capacidade do meio em tornar acessível a captura de áudios e imagens em movimento (vídeos) e imagens estáticas (fotografias) dos destinos turísticos. A portabilidade permitiria difundir essas imagens a outros suportes (celulares, computadores) de modo que outras pessoas pudessem visualizar e compartilhar essas imagens (representações).

Reiterou a necessidade de que a cidade estivesse bem cuidada, com ruas limpas e iluminadas, com o trânsito organizado, permitindo o registro de imagens positivas de Ilhéus, pois tal compartilhamento poderia ser potencializado através das redes sociais.

Assim, a velocidade da comunicação pode favorecer os destinos turísticos que estiverem atentos para a qualidade de vida no município. Esse pensamento é pertinente 
e condiz com a teoria das RS. Uma imagem capturada pelo turista ou residente, que é compartilhada com - e por - vários indivíduos, cai no senso comum e transforma-se numa representação (MOSCOVICI, 2003). Daí a necessidade de refletir sobre os diversos aspectos que permeiam a atividade turística.

Outros assuntos pontuais também entraram na pauta de discussão. Fatos que ocorreram ocasionalmente, mas com implicação direta na atividade turística. Chamouse a atenção para uma paralisação nos serviços dos caixas eletrônicos na principal agência bancária, localizada no centro de Ilhéus. Tal fato prejudicou o comércio local e o turista, que geralmente utiliza cartão de acesso a conta bancária, problema que afetou também os moradores.

\subsection{GESTÃO DO SETOR TURÍSTICO}

A gestão do turismo foi vista em diversos aspectos. Em algumas circunstâncias, as discussões se desdobraram sobre dados do turismo mundial, nacional e local. Por meio de comparações entre perspectivas e modelos de gestão de outros destinos, algumas críticas foram tecidas frente à administração municipal.

[...] eu entrevisto, via telefone, por exemplo, várias vezes a secretária de turismo de Bento Gonçalves. Porque Bento Gonçalves? Porque eu fiz um parâmetro (sic) em termos de tamanho com (sic) Ilhéus: cidade do interior, relativamente perto de capital... Muitas coisas acontecem lá e poucas coisas acontecem aqui (FIGUEROA, jun. 2011).

Em determinado programa, por exemplo, o locutor ressaltou que o Ministério do Turismo, traçando as diretrizes do turismo brasileiro, dava atenção ao turismo rural (região de vinhedos, engenhos de cana, região do café, região do cacau) e turismo de saúde. Alertou que a região possuía potencialidades que não estavam sendo exploradas, a exemplo das fazendas de cacau e das águas medicinais de Olivença.

Notou-se também uma crítica na forma do governo municipal distribuir os cargos nas secretarias, em especial da pasta de turismo. O locutor disse ser necessário romper o paradigma de nomear políticos partidários para ocupar determinados cargos. Segundo ele, o modelo de gestão estaria falido e os resultados do trabalho da Secretaria de Turismo seriam mais eficientes se esta fosse conduzida por um profissional de turismo, em especial um hoteleiro, por possuir conhecimentos específicos na área. Tais 
profissionais estariam mais aptos para solucionar problemas e promover o turismo da cidade de Ilhéus. Para tanto, fez uma comparação com o estado de Sergipe, onde o governador nomeou um hoteleiro como secretário.

[...] hoje nós não temos Secretaria de Turismo. O que nós temos é secretaria de festas e eventos. A única é (sic) intenção, e são bons nisso, demonstraram agora no triátlon, fizeram um trabalho bacana, se bem que o Triátlon é formatado pela associação de Banco do Brasil e Caixa Econômica Federal, mas enfim, se pensa São João, Carnaval, Triátlon, agora, e mais nada. [...] Muito pontuais (sic), que estão sendo feitas há vinte anos e tá (sic) mostrado por A mais B de que é (sic) não cabe mais (FIGUEROA, jun. 2011).

Houve críticas em relação à criação de um Conselho de Turismo para fortalecer e fiscalizar o setor. Tal crítica fundamentou-se na intenção de desenvolver o turismo local. Um conselho de turismo poderia, por exemplo, assegurar transparências em processos, propor alternativas, ajustes, procedimentos durante a execução de projetos turísticos, com a finalidade de minimizar os impactos ambientais e sociais da atividade.

No debate sobre os dividendos que a Copa do Mundo FIFA 2014 poderia trazer para o turismo nacional, questões de infraestrutura e gestão seriam concomitantes diante da possibilidade de Ilhéus, na época, se tornar subsede dos jogos da Copa. Para o locutor, seria preciso mobilização do governo municipal e investimento em infraestrutura para atrair os turistas de várias partes do mundo, entendendo que não só as sedes dos jogos seriam beneficiadas, como também os municípios em torno. Essa pauta foi estendida em outro programa quando se discutiu uma possível construção de um estádio para servir como centro de treinamento de seleções. $\mathrm{Na}$ oportunidade, foi criticada a falta de visão estratégica da prefeitura, visto que a cidade de Porto Seguro teria se adiantando à questão, mesmo estando mais afastada da capital, Salvador. A falta de planejamento e de políticas voltadas para o progresso do setor pode ser exemplificada na crítica:

[...] eu cheguei aqui em 1998, e todos nós ouvíamos de (sic) que Ilhéus é o terceiro polo de turismo da Bahia. Salvador, Porto Seguro, Ilhéus. Hoje é o quinto. São dados é (sic) do IPEA e o IPEA é uma instituição séria e que (sic) as pessoas não querem acreditar. Salvador, Porto Seguro, Mata de São João, Morro de São Paulo e Ilhéus. Morro de São Paulo com 4,3\% e Ilhéus com $2,8 \%$ [...] estamos longe do quarto. Estamos ainda olhando, nos identificando e invejando Itacaré, porque Itacaré é $0,7 \%$ do faturamento do turismo do estado da Bahia. Ou seja, insignificante (FIGUEROA, jun. 2011). 
Percebeu-se que o recurso de fazer comparações poderia ser usado como uma tentativa de provocação para causar espanto e posterior reflexão sobre as informações e dados apresentados. Foi com esse intuito, por exemplo, que em um dos programas o locutor falou do crescimento da China no mercado turístico, para mostrar que o Brasil, apesar de ter muitos potenciais, ainda não ocupava um lugar de destaque no contexto internacional.

De acordo com o relatório elaborado pelo Fórum Econômico Mundial, edição de 2011, publicado na reportagem da BBC Brasil, o Brasil apareceu na posição 52 entre 139 países avaliados (BBC BRASIL, 2011). Trazer a tona esse tipo de questionamento insere o morador em um universo mais amplo longe de suas percepções imediatas, tomando emprestadas as palavras de Ortriwano (1985).

\subsection{INCENTIVOS À ARTE, À CULTURA E AO LAZER}

Sobre produção radiofônica, Mcleish (2001) escreveu que o rádio deve contribuir para cultura artística e intelectual, cedendo espaços para artistas novos e consagrados. Estando a cultura aliada ao desenvolvimento do turismo, notou-se que esse setor ganhou considerável espaço nos temas ponderados no Coluna de Turismo. Assuntos relacionados à arte, à cultura e ao lazer estiveram presentes em 6 dos 10 programas analisados.

O Grupo Afro Dilazenze ${ }^{11}$ de Ilhéus, foi destacado pelas ações sociais desenvolvidas na comunidade, como dança, música, retirando crianças da rua, permitindo a inclusão social e cultural. O locutor lembrou ser importante este tipo de envolvimento principalmente quando existe uma carência de outros espaços culturais como bibliotecas e quadras de esporte em bairros periféricos. Alertou-se para os trabalhos desenvolvidos também no turismo, como a recepção que o grupo Dilazenze fazia aos turistas que chegavam nos navios. Esse contexto foi lembrado quando se noticiou uma possível paralisação nesses serviços, já que a Secretaria de Turismo de Ilhéus não estaria realizando o pagamento. Criticou-se a gestão municipal por tal circunstância demonstrar a desvalorização da cultura e do trabalho social desenvolvido pelo grupo, tendo em vista que a inclusão social ocorreria com o repasse das verbas.

\footnotetext{
${ }^{11}$ Grupo que promove ações educativas e socioculturais para preservação da cultura negra na cidade de Ilhéus (BA).
} 
O Festival de Cinema Baiano ${ }^{12}$ apareceu em diversas divulgações, tendo um programa inteiramente a ele destinado, com entrevista de cineasta que participava do evento. Comentários sobre filmes guiaram parte da entrevista, na qual se discutiu os incentivos do Ministério da Cultura, possibilitando a descentralização da produção cultural do eixo Rio - São Paulo. Nesse intuito - e na perspectiva de fomentar o turismo na região - o locutor levantou a hipótese e a viabilidade de o Festival de Cinema Baiano se transformar num evento permanente em Ilhéus, agregando uma imagem de diversidade cultural. Maior atenção foi dada ao filme Pau-Brasil justamente porque o título seria mote de um sorteio de ingressos. $\mathrm{O}$ ouvinte teria que responder a pergunta: qual a árvore símbolo do Brasil? Para incentivar a participação do morador no festival, ressaltou-se que, além das sessões pagas, existiram mostras gratuitas, enfatizando que o evento era destinado a todas as classes sociais.

Diante destes esforços para divulgar a cultura local, é importante fazer uma ressalva quanto à participação do ouvinte. Especificamente nesse dia, apesar de o programa tratar sobre cultura, turismo e cinema, percebeu-se que o público participante não interagiu com o tema. Com exceção do ouvinte que ligou para participar da promoção, todos os outros preferiram reclamar das condições de infraestrutura do município. Tal constatação remeteu à hipótese de que seriam esses os problemas mais latentes na sociedade local, interferindo diretamente no funcionamento da ordem social.

Porém, em outros momentos de interatividade, percebeu-se que os ouvintes se identificaram com os temas abordados no programa, tecendo-se elogios sobre empenho do locutor para que os moradores passassem a acreditar no potencial da cidade.

O Mercado de Artesanato de Ilhéus também apareceu nas veiculações. O locutor lembrou a variedade de objetos encontrados no mercado, enfatizando que cerca de $80 \%$ da população de Ilhéus não conhecia ou não costumava frequentar o local. Diante disso, convocou-se a população para apreciar o trabalho dos artistas, sugerindo aos ouvintes uma visita, ainda que não fosse para realizar compras.

$\mathrm{Na}$ proximidade do carnaval, o programa dedicou uma atenção maior aos artistas que iriam se apresentar. Ressaltou-se alguns blocos, divulgou-se o Projeto Otambi de

\footnotetext{
${ }^{12}$ O Festival de Cinema Baiano ocorre na cidade de Ilhéus, reunindo cineastas, estudantes, pesquisadores e admiradores do cinema.
} 
Verão, da Orquestra Afro Gongombira ${ }^{13}$. Advogou-se para que fossem contratados mais artistas locais. Divulgou-se também CD's de artistas ilheenses. Foi feita uma crítica ao porte do evento, entendendo que deveria haver maiores investimentos. Assim, aproveitou para mencionar equívocos da administração pública: trazer bandas de forró para tocar no carnaval e bandas de carnaval para animar o São João.

\subsection{MEIO AMBIENTE E TURISMO}

O programa destacou interesse ambiental ao inserir o quadro Coisas de Ilhéus, uma vez por semana, tendo como convidado o Presidente da Fundação Universidade Livre do Mar e da Mata - MARAMATA, Antônio Olímpio. Em determinado programa, o quadro dedicou atenção aos problemas ocasionados pela poluição do meio ambiente no município de Ilhéus. Em torno da temática, houve diversas abordagens: processos de formação dos estuários; poluição dos rios e manguezais; destruição das matas ciliares; invasão da população com construções irregulares em áreas de mangues; acúmulo de resíduos de esgotos e dejetos de indústrias que descem pelos rios e se acumulam nos manguezais.

De forma didática, abordou-se o prejuízo para a fauna e a flora causado pela poluição das águas e manguezais desses locais, ressaltando a importância do mangue enquanto ambiente restaurador e mantenedor da reprodução de diversas espécies, especialmente da fauna marítima. Do mesmo modo, alertou-se para os impactos da poluição na vida dos seres humanos, como, por exemplo, a falta de peixes e crustáceos. Advertiu-se que, uma vez que a poluição contaminasse a fauna e flora, colocar-se-ia em risco a saúde dos próprios moradores e turistas.

Entende-se que o debate sobre a poluição aquática é pertinente para o turismo, tendo em vista a relação direta do município de Ilhéus com as águas. Na perspectiva histórica, o povoamento da cidade ocorreu primeiramente nas proximidades dos rios e do mar, revelando a dinâmica das ocupações territoriais e das atividades produtivas que ali se estabeleceram (BUENO, 1999). No contexto socioeconômico, a poluição torna-se um agravante na medida em que interfere no trabalho dos pescadores e marisqueiros, gerando a falta de crustáceos, peixes, camarões entre outras espécies utilizadas na

\footnotetext{
${ }^{13}$ Orquestra de percussão da cidade de Ilhéus (BA) que reúne músicos com objetivo de resgatar, preservar e valorizar a música afro-brasileira.
} 
gastronomia local. A ausência desses alimentos poderia levar donos de bares e restaurantes a procurar outros mercados ou, de maneira ainda mais grave, poder-se-ia ofertar alimentos contaminados a turistas e a própria comunidade.

Com intuito de alertar para a necessidade de cuidar da qualidade das águas, outra questão que recaiu sobre o turismo foi a chegada das baronesas ${ }^{14}$ vindas pelos rios até praias e ao apodrecer causaram mau cheiro. O tema mobilizou o ouvinte que participou do debate defendendo a ideia de que o poder público municipal deveria agir de forma mais incisiva no combate à poluição. O morador se queixou da poluição gerada por outros municípios - especificamente do fluxo de lixo trazido da cidade vizinha, Itabuna, pelo Rio Cachoeira - prejudicando Ilhéus. Houve uma concordância nesse ponto de vista, ressaltando-se que seria preciso agir em conjunto, com medidas que dessem retorno em longo prazo. Contudo, o locutor reforçou que esse era um problema que cabia também ao município de Ilhéus, alertando que os próprios moradores poluíam. Evidenciou a representação, presente na mente do ouvinte, de que caberia ao poder público zelar e cuidar pelo patrimônio local.

O presidente da Fundação MARAMATA mencionou um projeto que visava limpar o manguezal da avenida Princesa Isabel e ressaltou a importância da educação para formar cidadãos capazes de agir de modo consciente. Já o locutor defendeu que dever-se-ia ter um projeto de recuperação da Bacia Leste do Estado como contrapartida para a instalação do Porto Sul ${ }^{15}$ em Ilhéus.

Essa abordagem aproxima o rádio dos ideais educativos dos primórdios da radiodifusão nacional, sendo essencial para o exercício da cidadania. Ao possibilitar o debate social e político sobre temas importantes e ao propor soluções práticas para atingir objetivos coletivos, entende-se que o programa cumpriu uma das funções sociais do veículo.

\footnotetext{
${ }^{14}$ A planta aquática também conhecida como aguapé; nome científico: Eichornia crassipes.

${ }^{15}$ Empreendimento do Governo do Estado da Bahia, o Porto Sul será construído no litoral norte de Ilhéus; faz parte da logística do governo para escoar a produção de grãos e minérios transportados pela Ferrovia de Integração Oeste-Leste (FIOL), obra do Governo Federal que ligará a cidade de Figueirópolis, no Tocantins, a Ilhéus, na Bahia (BAHIA, 2013).
} 


\subsection{DIVULGAÇÕES DE CAMPANHAS E SERVIÇOS}

Entre as campanhas veiculadas, chama-se atenção para uma que visava combater o abuso contra crianças e adolescentes. Realizada pelo Ministério do Turismo, a campanha foi reforçada pelo locutor que dirigiu o discurso para mobilizar os ouvintes, reforçando o número do telefone para denúncias e ressaltando que não seria necessária a identificação, no intuito de encorajar e mobilizar o ouvinte.

Outras campanhas veiculadas foram: alerta sobre o mosquito da dengue e os cuidados que precisavam ser redobrados na época do verão; campanha contra o consumo de crack na cidade de Ilhéus. Apareceram também alguns serviços informativos, como a divulgação do curso de qualificação de mão de obra para moradores, que era oferecido por uma mineradora.

Ao lançar luz no papel da cadeia produtiva do rádio e de seus conteúdos veiculados, entende-se que os meios de comunicação, aliados ao turismo, devem ultrapassar a simples ferramenta de propaganda para possibilitar uma reflexão que remeta a imagens das identidades, da memória coletiva e social de um povo, constituindo-se como suporte para o exercício da cidadania e preservação do patrimônio.

Apesar dessa pesquisa não ter a intenção de generalizar e decidir sobre uma forma de representação da cidade a partir dos meios de comunicação de massa, entendese que a investigação pode contribuir para reflexão e compreensão do rádio como veículo promotor da cultura e do turismo local.

\section{CONSIDERAÇÕES FINAIS}

O rádio apresenta-se como um espaço de legitimação e prestígio, no sentido que a imagem do radialista está associada à de um porta-voz social. Entendendo que as imagens e ideias estão intimamente relacionadas, percebeu-se a importância do veículo em difundir novas e outras imagens sobre a localidade em que a emissora se situa, pois as mudanças são precedidas de novas imagens mentais. Por isso, é de fundamental importância que os radialistas suscitem o debate junto à comunidade, difundindo a 
representação de que cabe ao residente também trabalhar em prol do desenvolvimento do turismo de modo equilibrado. Deve-se atentar, principalmente, que as ações realizadas pela administração pública surgem das demandas sociais e devem ser reflexos de decisões coletivas. É nesse sentido que o programa Coluna de Turismo surgiu como espaço de discussão, propondo reflexões sobre a realidade do turismo local.

Apesar do curto espaço na grade, com a massificação dos temas, o programa poderia contribuir para mudanças de representações, fazendo com que o morador percebesse seu lugar como turístico e enxergasse no turismo uma atividade importante em que, além do poder público e da iniciativa privada, ele também é responsável. Destacada a relevância dos temas tratados pelo programa, algumas questões poderiam ser ajustadas.

Existe a necessidade de cumprimento da legislação em vigor - Lei $\mathrm{n}^{\circ} 9.612$ - no que diz respeito à divulgação de publicidade (BRASIL, 1998). Pelo caráter comunitário seria imprescindível que os esforços fossem somados no sentido de apoios culturais e não em troca de propagandas com venda de marcas e ideias de algumas empresas. Além disso, levando em consideração que o fato de o locutor não ter formação específica em rádio e televisão ou jornalismo, para auxiliar na produção, poder-se-ia firmar parceria com universidades que oferecem o curso de comunicação para ofertar estágio na área.

A possibilidade de veicular o programa na Internet é plausível, na medida em que diminui custos de produção e rompe limites geográficos. Entretanto, isso retiraria do programa sua principal característica: debater o turismo com a comunidade. É importante lembrar que apesar do acesso à grande rede de computadores ser uma realidade para muitos brasileiros, a inclusão digital não avançou significativamente para permitir o acesso de todos. Nesse âmbito, o rádio ainda continua sendo o meio mais comunitário.

Levando-se em consideração a limitação prevista na legislação das emissoras comunitárias e entendendo a importância da difusão de informações e do debate sobre o turismo local, seria oportuno que o formato do programa fosse adotado por outras emissoras comerciais que têm maior abrangência no território do município.

Além das informações como hora certa, temperatura do ar, clima, condições das águas, maré, condições do trânsito, dicas de segurança no mar, poderiam ser 
distribuídos na programação. De modo semelhante, seria viável a veiculação e ampliação de campanhas educativas que promovessem preservação do meio ambiente, manutenção do patrimônio histórico e arquitetônico.

O planejamento do turismo deve levar em consideração que as ações empreendidas no campo das mudanças de comportamento interatuam com representações e práticas enraizadas e que, por isso, necessitam de discussões contínuas para que as mudanças sejam visíveis, ainda que em longo prazo.

\section{REFERÊNCIAS}

ALVES, C. R. A paisagem acústica da cultura e do turismo na cidade de Ilhéus, Bahia, a partir do rádio local. 2012. 123 f. Dissertação. Universidade Estadual de Santa Cruz. Programa de Pós-graduação em Cultura e Turismo. Ilhéus: UESC, 2012.

ANATEL. AGÊNCIA NACIONAL DE TELECOMUNICAÇÕES. Disponível em: <http://www.anatel.gov.br/Portal/exibirPortalInternet.do>. Acesso em: 01/08/2013.

ARNHEIM, R. O diferencial da cegueira: estar além dos limites dos corpos. In: MEDITSCH, E. (Org.). Teorias do rádio: textos e contextos: v. 1. Florianópolis, SC: Insular, 2005. p. 61-98.

BAHIA, Secretaria de Cultura e Turismo. Superintendência de Desenvolvimento do Turismo. Roteiros ecoturísticos da Bahia da Costa do Dendê. Salvador, 2001.

Casa Civil. Audiências públicas do Porto Sul são exemplos para a Bahia. Disponível em: $<$ http://www.casacivil.ba.gov.br/index.php?option=com_content $\&$ view=article $\& i d=276$ \&Itemid=99\&pagina=2>. Acesso em: 20/12/2013.

BARBOSA FILHO, A. Gêneros Radiofônicos. SP: Paulinas, 2003.

BBC BRASIL. Brasil perde posições em ranking mundial do turismo.

Disponível em:

$<$ http://www.bbc.co.uk/portuguese/noticias/2011/03/110307_turismo_ranking_pu.shtml >. Acesso em: 15/06/2011.

BIANCO, N. R. E tudo vai mudar quando o digital chegar. In: FILHO, A. B.; PIOVESAN, A.; BENETON, R. (Org.). Rádio: sintonia do futuro. São Paulo: Paulinas, 2004. 
BRASIL. Lei $\mathrm{n}^{\circ}$ 9.612, de 19 de fevereiro de 1998. Institui o Serviço de Radiodifusão Comunitária. Disponível em: <https://www.planalto.gov.br/ccivil_03/Leis/L9612.htm>. Acesso em: 21/05/2011.

BUENO, E. A Costa do Pau-Brasil: A Bahia e as Capitanias do Centro. In: Capitães do Brasil: a saga dos primeiros colonizadores. Rio de Janeiro: Objetiva, 1999, 288 p. Coleção Terra Brasilis. v. 3, parte 4, p. 217-275.

COGO, D. M. No ar...: uma rádio comunitária. São Paulo: Paulinas, 1998.

COMASSETTO, L. R. A Voz da Aldeia: o rádio local e o comportamento da informação na nova ordem global. Florianópolis: Editora Insular, 2007.

CORIOLAnO, L. N. M. T. Do local ao global: O Turismo Litorâneo Cearense. Campinas, SP: Papirus, 1998.

ESCH, C. E. O futuro dos comunicadores e a reinvenção do rádio. In: BIANCO, N. R.; MOREIRA, S. V. (Orgs.). Desafios do rádio no século XXI. São Paulo: INTERCOM; Rio de Janeiro: UERJ, 2001. p. 77-91.

FIGUEROA, A. Ariel Figueroa: depoimento [jun. 2011]. Entrevistador: ALVES, C. R. Ilhéus-BA, 2011. Arquivo sonoro digital (18 min.). Entrevista concedida ao projeto de mestrado A Paisagem Acústica da Cultura e do Turismo na cidade de Ilhéus, Bahia, a partir do rádio local.

IGNARRA, L. R. Fundamentos do turismo. 2. ed. São Paulo: Pioneira, 2003.

MCLEISH, R. Produção de Rádio: um guia abrangente da produção radiofônica. São Paulo: Summus, 2001.

MCLUHAN, M. Os meios de comunicação como extensões do homem. 13 ed. São Paulo: Cultrix, 2003.

MOSCOVICI, S. Representações sociais: investigações em psicologia social. Rio de Janeiro, Vozes, 2003.

ORTRIWANO, G. S. A informação no radio: os grupos de poder e a determinação dos conteúdos. São Paulo: Summus Editorial, 1985.

PAULA FREITAS, A.; MACIEL, F.; NASCIMENTO, J.; CAVALCANTI, A.; REIS, T.; ANDRADE FILHO, J.; NEVES, E. Memória do Rádio Grapiúna. In: IV ENCONTRO NACIONAL DA REDE ALFREDO DE CARVALHO, 4., 2006, São Luís, MA. Anais (on line). Disponível em: <http://www.ufrgs.br/alcar/encontrosnacionais-1/4o-encontro-2006-1>. Acesso em 15/02/2011.

PENA, F. Teorias do Jornalismo. São Paulo: Contexto, 2005.

SÁ, R. B. A imagem do Brasil no turismo. São Paulo: Editora Aleph, 2002. 
SANTOS, M. I. D. A. Gênero e comunicação: o masculino e o feminino em programas populares de rádio. São Paulo: Annablume, 2004.

TRIGO, L. G. G. Turismo Básico. 7. ed. São Paulo: Editora Senac, 2004.

Recebido em: 30-04-2013.

Aprovado em: 29-05-2013. 